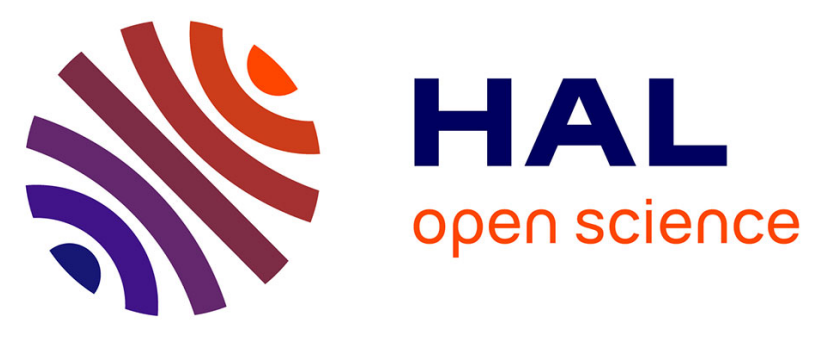

\title{
Minor Blunt Thoracic Trauma in the Emergency Department: Sensitivity and Specificity of Chest Ultralow-Dose Computed Tomography Compared With Conventional Radiography
}

Francesco Macri, Joel Greffier, Elina Khasanova, Pierre-Geraud Claret, Sophie Bastide, Ahmed Larbi, Xavier Bobbia, F. Pereira, Jean-Emmanuel de La Coussaye, Jean P. Beregi

\section{- To cite this version:}

Francesco Macri, Joel Greffier, Elina Khasanova, Pierre-Geraud Claret, Sophie Bastide, et al.. Minor Blunt Thoracic Trauma in the Emergency Department: Sensitivity and Specificity of Chest UltralowDose Computed Tomography Compared With Conventional Radiography. Annals of Emergency Medicine, 2019, 73 (6), pp.665-670. 10.1016/j.annemergmed.2018.11.012 . hal-02935393

\section{HAL Id: hal-02935393 \\ https://hal.umontpellier.fr/hal-02935393}

Submitted on 25 Oct 2021

HAL is a multi-disciplinary open access archive for the deposit and dissemination of scientific research documents, whether they are published or not. The documents may come from teaching and research institutions in France or abroad, or from public or private research centers.
L'archive ouverte pluridisciplinaire HAL, est destinée au dépôt et à la diffusion de documents scientifiques de niveau recherche, publiés ou non, émanant des établissements d'enseignement et de recherche français ou étrangers, des laboratoires publics ou privés.

\section{(ㄷ)(1) $\$$}

Distributed under a Creative Commons Attribution - NonCommerciall 4.0 International 


\section{Minor blunt thoracic trauma in the emergency department: sensitivity and specificity of chest ultra- low-dose computed-tomography compared to conventional radiography.}

Francesco Macri, MD-PhD ${ }^{\text {a, b}}$; Joel Greffier, PhD ${ }^{\text {b}}$; Elina Khasanova, MD-MS ${ }^{\text {a, b}}$; Pierre-Geraud Claret, MD-PhD ${ }^{\text {c; }}$ Sophie Bastide, MD-PhD ${ }^{\text {d }}$; Ahmed Larbi, MD ${ }^{\text {b; }}$ Xavier Bobbia, MD ${ }^{\mathrm{c}}$; Fabricio R. Pereira, $\mathrm{PhD}{ }^{\mathrm{b}}$; Jean de la Coussaye, MD-PhD c; Jean Paul Beregi, MD-PhD ${ }^{b}$

a Department of Emergency and Trauma Radiology, Vancouver General Hospital, University of British Columbia, Vancouver, BC, Canada.

${ }^{b}$ Department of Radiology, CHU Nîmes, University of Montpellier, Medical Imaging Group Nîmes, EA 2415, Nîmes, France

${ }^{c}$ Department of Emergency Care and Traumatology, CHU Nimes, University of Montpellier, Nimes, France

${ }^{d}$ Department of Biostatistics, Public Health, Epidemiology and Innovation in Methodology (BESPIM), CHU Nimes, University of Montpellier, Nimes, France 
Corresponding author: Francesco Macri, MD-PhD, Vancouver General Hospital, Jim Pattison Pavilion South, 899 West $12^{\text {th }}$ Ave., Vancouver BC V5Z 1M9, BC, Canada

Tel: +1.604.875.4111; fax: +1.604.875.4508; mail: francesco.macri@yahoo.it 


\section{Acknowledgements}

We thank Sarah Kabani for the English revision of the paper. The authors state that this work has not received any funding.

\section{Author contributions.}

- Francesco Macri; design and responsible for authorization and implementation of the study, one of the blind readers for images, writing the paper

- Joel Greffier; CT scan optimization to perform ULD-CT, dose recording, statistical analysis, writing manuscript

- Elina Khasanova; blind reader of all images

- Pierre-Geraud Claret; selection of the patients, help for discussion

- Sophie Bastide; confirmed all statistical analysis done by Fabricio Pereira and Joël Greffier

- $\quad$ Ahmed Larbi; help for discussion, CT image optimization

- Xavier Bobbia; selection of the patients, help for discussion

- Fabricio R. Pereira; help for discussion, statistics, writing manuscript

- Jean de la Coussaye; design of the study, help for discussion, writing manuscript

- Jean Paul Beregi, design of the study, help for discussion, writing manuscript 


\section{ABSTRACT}

Objectives. To evaluate the diagnostic performance of a chest ultra-low-dosecomputed-tomography (ULD-CT) compared to a chest X-ray (CXR) for minorblunt-thoracic-trauma (MBTT).

Methods. One hundred and sixty MBTT patients were explored first by CXR, and subsequently with a double acquisition non-enhanced chest CT protocol: reference CT (Ref-CT) and ULD-CT with iterative reconstruction (IR). Two study radiologists (SRs) independently assessed injuries using a structured report and subjective image quality and calculated certainty of diagnostic confidence level (DCL).

Results. ULD-CT had a sensitivity and specificity of $100 \%$ compared to Ref-CT in the detection of injuries (187 lesions) in 104 patients. CXR detected abnormalities in 82 patients (79\% of the population) with lower sensitivity and specificity compared to ULD-CT $(p<0.05)$. Despite an only fair inter-observer agreement for ULD-CT image quality $(\mathrm{k}=0.26)$, the $\mathrm{DCL}$ was certain in $95.6 \%$ (CXR=79.3\%). ULD-CT effective dose $(0.203 \pm 0.029 m S v)$ was similar $(p=0.136)$ to CXR dose $(0.175 \pm 0.155 \mathrm{mSv})$ and significantly less $\left(p=7.98 \times 10^{-15}\right)$ than RefCT $(1.193 \pm 0.459 \mathrm{mSv})$.

Conclusions. ULD-CT with IR conveyed a similar radiation dose compared to CXR and was more reliable than a radiographic study for MBTT assessment. Radiologists, regardless of experience with ULD-CT, were more confident on chest ULD-CT than on chest CXR. 


\section{Keywords}

Minor blunt thoracic trauma; Ultra-low-dose chest CT; Chest X-ray; Emergency room; Radiation safety. 


\section{Introduction}

\section{Background}

Thoracic injuries are frequent, with significant morbidity and mortality. Management of patients mostly depends on the mechanism of the injury, age of the patient and gravity of the symptoms [1, 2]. The Vittel criteria [3] are part of a triage algorithm used by first response crew in France for managing trauma patients prior to admission. The diagnosis of severe trauma is made based on the presence of one single criterion (other than predisposition), which results in the most critical patients being directed toward a specialized traumatology center. A "severe" trauma patient, according to the Vittel criteria, corresponds to a patient with at least one potentially life-threatening or disabling injury, or who sustained trauma whose mechanism or severity suggests that such lesions may exist. When no criterion is present, Chest X-ray (CXR) is the first-line imaging for suspicion of chest lesion in thoracic trauma. Although Computed Tomography (CT) has a higher sensitivity and specificity than CXR in the evaluation of these patients [2, 4], it is usually used in second-line because of its higher irradiation.

\section{Importance}

In the recent years, technological improvements such as iterative reconstruction (IR) have become available and have improved the radiation safety of the patients in CT. The IR reduces the noise of a CT image generated with a lowered dose [5]. The IR allows an ultra-low-dose-CT (ULD-CT), with a dose in the range of the $\mathrm{CXR}$, while preserving a diagnostic image quality despite 
a noisier image [6]. Hence the ULD-CT can obviate excessive radiation dose exposure of a standard CT for the evaluation of minor-blunt-thoracic-trauma (MBTT) patients.

\section{Objective}

The primary objective of this study was to compare the sensitivity and specificity (globally and per lesion type) of chest ULD-CT against CXR for MBTT patients in the emergency department, the diagnostic performances being evaluated against a reference CT (Ref-CT). 


\section{Materials and Methods}

\section{Study design}

This was a cross-sectional single-center diagnostic study. Patients were prospectively recruited from October 2016 to March 2017. The Institutional Review Board of our institution (Level I trauma center) approved this study $\left(\mathrm{N}^{\circ} 1886494\right)$, providing that total irradiation per patient $(\mathrm{CXR}+\mathrm{CTs})$ did not exceed the national diagnostic reference level (DRL) of a chest CT [7].

\section{Population}

Participants were identified in our emergency and traumatology department and were included in the availability periods (convenience sample) of the ULD-CT scan (8AM to 6PM from Monday to Friday). Inclusion criteria were: hemodynamically stable patients older than 18 years that sustained a kinetic energy trauma (motor vehicle accident, fall down the stairs, etc.). The exclusion criteria were patients with unstable hemodynamic conditions (fall of the blood pressure $>30 \%$ or systemic pressure $<110 \mathrm{mmHg}$ ), dyspnea, with loss of consciousness or with at least one Vittel criterion [3].

\section{Settings}

Patients systematically underwent the CXR as a first step, with rib series when rib fractures were suspected by emergency physicians or radiologists (125kVp and 70kVp, respectively; Digital Diagnostic X-ray room; Philips, Amsterdam, Netherlands), immediately (<30 minutes later) followed by a CT examination as a second step. Chest CT images were performed on a 64-Multidetector-computed-tomography (Definition AS+, Siemens Healthineers, 
Forcheim, Germany). Patients lay in supine position for a Ref-CT (100kVp, 60mAs, CareDose-4D activated, pitch 1.5) and an ULD-CT (100kVp, 10mAs fixed, pitch 1.5). Both acquisitions were acquired consecutively without intravenous injection of contrast media. The tube current parameters were fixed for ULD-CT to be below the national dose reference level for a CXR (Effective dose (E): $0.225 \mathrm{mSv}$ ) [7]. ULD-CT images were reconstructed with IR (SinogramAffirmed-Iterative-Reconstruction [SAFIRE]).

\section{Data collections}

Two independent study radiologists (SRs), with nine (F.M. [SR1]) and six (E.K. [SR2]) years of experience as board certified radiologists, independently assessed anonymized CXR and ULD-CT datasets on clinical workstations with PACS viewer system (Centricity, GE Healthcare, Wisconsin, USA) in a random fashion and with at least two weeks between each data reading session. SRs were not aware of clinical data of the patients. SR1 had three years of experience with ULD-CT images whereas SR2 had no experience in chest ULDCT (only two-week training period in view of this study). Ref-CT images were read by the scheduled radiologists during the regular shifts (excluding SR1 and SR2) who were informed of the final diagnosis. SRs evaluated the imaging to detect the presence of pneumothorax, subcutaneous emphysema, pneumomediastinum, pulmonary contusion, fractures of the thoracic skeleton (thoracic spine, rib cage, clavicles and sternum), pleural effusion, pericardial ( $>2 \mathrm{~mm}$ thickness) and pleuro-pericardial effusions. The primary outcome was the 
presence of at least one lesion. Number of rib fractures or severity of effusions were not evaluated.

The subjective image quality of the CXR and ULD-CT was evaluated using a 5point Likert scale: 1, excellent; 2, good; 3, fair; 4, poor; 5, unacceptable [6]. SRs expressed for each patient and for the two modalities a diagnostic confidence level (DCL) as certain or uncertain.

The radiation dose was evaluated by calculating the effective doses $(E)$. DoseArea-Product (DAP) for the CXR and the Dose-Length-Product (DLP) for the ULD-CT and the Ref-CT were recorded from the dose report of each patient and converted to $\mathrm{E}$. E was calculated by multiplying the DLP and the DAP by normalised effective dose conversion coefficient for the chest: 0.014 mSv.mGy ${ }^{1} \cdot \mathrm{cm}^{-1}$ for the CT and $0.00018 \mathrm{mSv} \cdot \mathrm{mGy}^{-1} \cdot \mathrm{cm}^{-2}$ for the radiography.

\section{Statistical analyses}

The sensitivity and specificity of ULD-CT and CXR were estimated, with 95\% of confidence intervals [95\% Cl], against the Ref-CT (reference standard) globally and per lesion type. SR1 results were used for diagnostic performance estimations. Concordance between SRs (inter-observer agreement) was assessed with kappa and weighted kappa statistics [with their 95\% Cl] globally and per lesion type. Hodges-Lehmann estimator was computed to test the effective dose differences between ULD-CT versus CXR and ULD-CT versus Ref-CT. All analyses were performed using R software using a two-sided type 1 error rate of $5 \%$ as a threshold for statistical significance. The sample size was calculated on the expected difference between the sensitivities of ULD-CT and 
CXR. With a hypothesis that $60 \%$ of the study population would present at least one lesion, 154 patients are necessary to show a sensitivity increase from $80 \%$ to $95 \%$ (with a two-sided type 1 error rate of $5 \%$ and a $90 \%$ power). To be conservative, 160 patients were planned to be included. 


\section{Results}

\section{Patients}

A total of 160 patients were included and all evaluated by CXR and CTs (14 minutes average time lapse between the two examinations; range from 5 to 30 ) to detect chest lesion. Patients mean age was $65 \pm 21$ years old with a mean body mass index (BMI) of $23.9 \pm 5.4 \mathrm{~kg} \cdot \mathrm{m}^{-2}$. Of 160 patients, $98(61 \%)$ were men (age $61 \pm 20$ years; BMl 23.8 $\pm 5.8 \mathrm{~kg} \cdot \mathrm{m}^{-2}$ ) whereas 62 (39\%) were women (age $69 \pm 22$ years; BMI $24.0 \pm 5.0 \mathrm{~kg} \cdot \mathrm{m}^{-2}$ ).

\section{Image assessment}

Among these 160 patients, Ref-CT showed pathological findings in 104 patients (65\%) with 187 lesions. A single lesion was found in 52 (50\%) of the patients. Two lesions were found in 32 patients (31\%). A total of 16 patients $(15 \%)$ presented three lesions and four patients $(4 \%)$ had at least four lesions. Figure 1 describes all the lesions and whether they were detected by each SR for each index test.

All patients with at least one injury related to the MBTT were detected on ULDCT (100\%, [97 - 100] sensitivity) but only 82 patients (79\%, [70 - 86] sensitivity) were observed on CXR. ULD-CT had no false positive results (100\% [94 - 100] specificity) whereas CXR had false positive results in 8 patients (86\% [74 - 94] specificity) with respect to the pleural effusion, which was over-estimated, being confused with pulmonary contusions. Table 1 presents the results of sensitivities and specificities globally and per lesion type. ULD-CT resulted in $100 \%$ both for 
sensitivity and specificity for all considered abnormalities. In contrast, sensitivities of CXR were low, specifically for pulmonary contusion $(4 / 17 ; 24 \%)$. CXR specificities were $100 \%$ except for effusion (89\% [80 - 94]) due to one false positive. Notably, pericardial effusions could only be diagnosed on CT $(26+10$ patients, $23 \%$ of population). Subjective image quality per SR is reported in Table 2. The inter-observer agreement for image quality was moderate $(k=0.26[0.17-$ 0.35]) for ULD-CT and good ( $k=0.85[0.74-0.96])$ for CXR. The DCL on CXR images was rated certain in $81.8 \%$ [75.9 - 87.9] and 79.3\% [73.1 - 85.7] of cases, respectively for SR1 and SR2. The DCL for ULD-CT was certain in 96.8\% [94.2 - 99.6] and 95.6\% [92.4 - 98.8] of cases for SR1 and SR2 respectively. Finally the inter-observer agreement for DCL was certain for CXR and ULD-CT respectively (CXR: $\mathrm{k}=0.92$ [0.84 - 1.00]; ULD-CT: $\mathrm{k}=0.83$ [0.59-1.00]).

Regarding the dose level, ULD-CT was significantly lower than Ref-CT $(\hat{\Delta}=0.93$; $[0.86-1.00])$ but not significantly different from CXR ( $\hat{\Delta}=0.06 ;[0.10-0.20])$. 


\section{Limitations of the study}

The first limitation of the study concerns practices that differ between centers in terms of trauma management. Our population, older and with a low BMI, might not reflect the population from other centres. Definition of pleural or pericardial effusions could be assessed differently, depending on the size of the effusion and the impact for the management of the patient. Difference between small or extensive effusion, number of rib fractures, or clinical impact on patients was not recorded. ULD-CT cost is higher than a CXR. A comparison with standard chest CT (5 to $7 \mathrm{mSv}$ ) was not done as for four years we have been routinely performing the low-dose chest CT (1 to $2 \mathrm{mSv}$ ) whose diagnostic reliability is promoted by a vast literature. In spite of the rigorous method of analysis between the two SRs, data were anonymised rather than de-identified, which might have influenced SRs reviewing.

\section{Discussion}

This study demonstrated that a chest ULD-CT with IR allows a more indepth assessment than a CXR for MBTT patients, delivering a radiation dose lower than the national CXR DRL. Moreover, the radiologist with a short training (SR2) in ULD-CT imaging was more confident on such CT imaging, despite the modification of the image quality due to the lowered dose and IR application, than on standard CXR.

The SRs found more injuries related to MBTT on ULD-CT than on CXR. Small pneumothorax and pneumomediastinum should not be underestimated because 
of the incidence of aggravation and potential broncho-digestive damage [8], respectively. ULD-CT, compared to CXR, had a very high sensitivity and specificity in detecting pulmonary contusions. The ULD-CT allowed a thorough study of the rib cage, thoracic spine and occasionally of the shoulder girdle. The versatility of 2D/3D CT images and their multiplanar reconstructions avoided the inconvenience of structure superimposition generated by plain radiographs, with misleading interpretations. Rib fractures are extremely painful during regular breathing and if overlooked they are a critical factor of mortality increase in elderly patients, especially with comorbidity [9]. Overall, SRs counted more pleural effusions on ULD-CT than on CXR. The pericardial effusions were seen only on ULD-CT due to low volumes making them non-visible with CXR. Pleural and pericardial effusions are frequent in this study due to conservative cut-off for effusion (definition $>2 \mathrm{~mm}$ ) with unpredictable clinical course [10]. Effusions are not necessarily hemorrhages and could have been present prior to the trauma. Also, elderly individuals with low BMI form a particular population, more fragile to traumas involving minor mechanisms of injury. Sensitivity and specificity values of the ULD-CT were higher than those of CXR, in keeping with the published literature for the standard CT [4].

The major issue of CT dose reduction is reduction in image quality due to increased noise. SAFIRE decreases the noise but when high strengths are applied, a smoothing effect can occur, which can initially confuse a nonaccustomed radiologist. SRs had a fair inter-observer agreement for ULD-CT. SR1 scored the majority of cases excellent for image quality whereas SR2 rated 
them good. SR2 was trained for ULD imaging specifically for this study, whereas SR1 had dealt with ULD for three years. It is noteworthy that SRs never considered the image quality poor or unacceptable for ULD-CT. SR2 and SR1 had a higher DCL on ULD-CT than on CXR (96\% vs $80 \%)$. This result highlights that even though SR2 was new and less satisfied with the image quality of ULDCT, finally proved more confident on ULD-CT than on standard radiographs.

In conclusion, ULD-CT with IR allows a thorough study of MBTT patients with lower radiation-induced cancer risks, suggesting a new approach for the MBTT work-up. Other studies should be conducted to define whether this initial major expense, which allows a more reliable and quick assessment, avoids further elevated health costs in the management of MBTT patients. 


\section{Figure legend}

Figure 1. Lesions detected on chest Ref-CT (reference standard), chest ULD-CT and CXR (two index tests) by two radiologists (SR1 and SR2). Ref-CT: reference computed-tomography; ULD-CT: ultra-low-dose computedtomography; CXR: chest $X$ ray; * corresponds to $p<0.05$ for SR1 between CXR and ULD. + corresponds to $p<0.05$ for SR2 between CXR and ULD. 


\section{REFERENCES}

1. Rodriguez RM, Angllin D, Langdorf MI, et al. NEXUS Chest : validation of a decision instrument for selective chest imaging in blunt trauma. JAMA Surg. 2013;148:940-946.

2. Langdorf MI, Medak AJ, Hendey GW, et al. Prevalence and clinical import of thoracic injury identified by chest computed tomography but not chest radiography in blunt trauma : multicenter prospective cohort study. Ann Emerg Med. 2015;66:589-600.

3. Babaud J, Ridereau-Zins C, Bouhours G, Lebigot J, Le Gall R, Bertrais S, Roy PM, Aubé C. Benefit of the Vittel criteria to determine the need for whole body scanning in a severe trauma patient. Diagn Interv Imaging. 2012;93:371-379. 351.

4. Exadaktylos AK, Sclabas G, Schmid SW, Schaller B, Zimmermann H. Do we really need routine computed tomographic scanning in the primary evaluation of blunt chest trauma in patients with "normal" chest radiograph? J Trauma. 2001;51:1173-1176.

5. Greffier J, Macri F, Larbi A, Fernandez A, Khasanova E, Pereira F, et al. Dose reduction with iterative reconstruction: Optimization of CT protocols in clinical practice. Diagn Interv Imaging. 2015;96:477-486.

6. Macri F, Greffier J, Pereira F, Rosa AC, Khasanova E, Claret PG, et al. Value of ultra-low-dose chest CT with iterative reconstruction for selected emergency room patients with acute dyspnea. Eur J Radiol. 2016;85:1637-1644. 
7. Government F. Arrêté du 24 octobre 2011 relatif aux niveaux de référence diagnostiques en radiologie et en médecine nucléaire. In: Ministry of Work MoH, editor. Journal officiel de la Republique Francaise: French Government; 24 october 2011. p. 715.

8. Rezende-Neto JB, Hoffmann J, Al Mahroos M, Tien H, Hsee LC, Spencer Netto F, et al. Occult pneumomediastinum in blunt chest trauma: clinical significance. Injury. 2010;41:40-43.

9. Bulger EM, Arneson MA, Mock CN, Jurkovich GJ. Rib fractures in the elderly. J Trauma. 2000;48:1040-1046; discussion 46-47.

10. Ganie FA, Lone H, Lone GN, Wani ML, Singh S, Dar AM, et al. Lung Contusion: A Clinico-Pathological Entity with Unpredictable Clinical Course. Bull Emerg Trauma. 2013;7-16. 

Table 1. Sensitivity and specificity (and their respective Cl 95\%) for chest X-ray (CXR) and chest ultra-low-dose-computed-tomography (ULD-CT) compared to the reference computed-tomography (Ref-CT).

\begin{tabular}{|c|c|c|c|c|}
\hline & \multicolumn{2}{|c|}{ CXR } & \multicolumn{2}{|c|}{ ULD-CT } \\
\hline & Sensitivity & Specificity & Sensitivity & Specificity \\
\hline \multirow{3}{*}{$\begin{array}{l}\text { At least } \\
\text { one lesion }\end{array}$} & 82 / 104 & 48 / 56 & $104 / 104$ & $56 / 56$ \\
\hline & $78.8 \%$ & $85.7 \%$ & $100.0 \%$ & $100.0 \%$ \\
\hline & [69.7-86.2] & {$[73.8-93.6]$} & {$[96.5-100.0]$} & {$[93.6-100.0]$} \\
\hline \multicolumn{5}{|l|}{ By lesion type: } \\
\hline $\begin{array}{l}\text { Pneumothorax } \\
(n=22)\end{array}$ & $\begin{array}{c}81.8 \% \\
{[61.5-92.7]}\end{array}$ & $\begin{array}{c}100.0 \% \\
{[97.3-100.0]}\end{array}$ & $\begin{array}{c}100.0 \% \\
{[85.1-100.0]}\end{array}$ & $\begin{array}{c}100.0 \% \\
{[97.3-100.0]}\end{array}$ \\
\hline $\begin{array}{l}\text { Subcutaneous } \\
\text { emphysema } \\
(n=22)\end{array}$ & $\begin{array}{c}72.7 \% \\
{[51.9-86.9]}\end{array}$ & $\begin{array}{c}100.0 \% \\
{[97.3-100.0]}\end{array}$ & $\begin{array}{c}100.0 \% \\
{[85.1-100.0]}\end{array}$ & $\begin{array}{c}100.0 \% \\
{[97.3-100.0]}\end{array}$ \\
\hline $\begin{array}{l}\text { Pneumomediastinum } \\
(\mathrm{n}=10)\end{array}$ & $\begin{array}{c}60.0 \% \\
{[31.3-83.2]}\end{array}$ & $\begin{array}{c}100.0 \% \\
{[97.5-100.0]}\end{array}$ & $\begin{array}{c}100.0 \% \\
{[72.3-100.0]}\end{array}$ & $\begin{array}{c}100.0 \% \\
{[97.5-100.0]}\end{array}$ \\
\hline $\begin{array}{l}\text { Fractures of the } \\
\text { thoracic skeleton } \\
(n=28)\end{array}$ & $\begin{array}{c}71.4 \% \\
{[52.9-84.8]}\end{array}$ & $\begin{array}{c}100.0 \% \\
{[97.2-100.0]}\end{array}$ & $\begin{array}{c}100.0 \% \\
{[87.9-100.0]}\end{array}$ & $\begin{array}{c}100.0 \% \\
{[97.2-100.0]}\end{array}$ \\
\hline $\begin{array}{l}\text { Effusions } \\
(n=88)\end{array}$ & $\begin{array}{c}59.1 \% \\
{[48.7-68.8]}\end{array}$ & $\begin{array}{c}88.9 \% \\
{[79.6-94.3]}\end{array}$ & $\begin{array}{c}100.0 \% \\
{[95.8-100.0]}\end{array}$ & $\begin{array}{c}100.0 \% \\
{[94.9-100.0]}\end{array}$ \\
\hline $\begin{array}{l}\text { Pulmonary } \\
\text { Contusion } \\
(n=17)\end{array}$ & $\begin{array}{c}23.5 \% \\
{[9.5-47.3]}\end{array}$ & $\begin{array}{c}100 \% \\
{[97.4-100.0]}\end{array}$ & $\begin{array}{c}100.0 \% \\
{[81.6-100.0]}\end{array}$ & $\begin{array}{c}100.0 \% \\
{[97.4-100.0]}\end{array}$ \\
\hline
\end{tabular}

Study radiologist 1 results were compared to the reference standard results (RefCT reports made by shift radiologists) for the sensitivity and specificity analyses. 
Table 2. Subjective image quality of chest X-Ray and chest ultra-low-dose CT

\begin{tabular}{lcccccc}
\cline { 2 - 7 } & \multicolumn{3}{c}{ CXR } & \multicolumn{3}{c}{ ULD-CT } \\
\cline { 2 - 7 } & SR1 & SR2 & Kappa & SR1 & SR2 & Kappa \\
\hline Excellent & 140 & 135 & & 132 & 59 & \\
\hline Good & 9 & 14 & & 21 & 94 & \\
Fair & 5 & 6 & 0.85 & 7 & 7 & 0.26 \\
Poor & 6 & 5 & {$[0.74-0.96]$} & 0 & 0 & {$[0.17-0.35]$} \\
Unacceptable & 0 & 0 & & 0 & 0 & \\
\hline
\end{tabular}

Study radiologist (SR) 1 and 2 with inter-observer agreement (weighted kappa estimations with 95\% Confidence Interval). CXR: chest X ray; ULD-CT: ultra-lowdose computed-tomography. 